\title{
India's Regional Development Experience in 1980-2000
}

\begin{abstract}
K.R.G. NAIR*
Abstract

This study is a preliminary investigation of the nature of change in inter-regional disparities in economic and social development in India, in the light of the prevalent views in this regard across the world. Attention is particularly focused on a comparison between India's regional experience in the pre- and in the post-reform periods, with the year 1990-1991 being considered as the dividing line between the two periods. The article is divided for analytical convenience into seven parts. Part one is introductory and gives the raison d'être for this study. Part two goes on to give the scope, nature of data and methodology used in the study. Part three contains an examination of the prevalent views regarding the pattern of regional change during the process of national economic development. Parts four and five examine India's regional experience in the pre- and post-reform periods in the light of these views. The sixth part compares the regional development experience of the country between the pre- and the post-reform periods. The concluding part brings together the main findings of the study attempting also to draw some broad policy inferences.
\end{abstract}

JEL Classification : R11

Keywords: Spatial Trickle-down, Economic Reforms, Development Indicators, Regional Change

\section{Raison d'être for the Study}

India is a large federal nation and it is well known that there are widespread disparities in the level of economic and social development between the different regions of the Indian nation. It is generally recognized that inter-regional economic disparities increase, at least in the initial stages of national economic development. As a result, governments everywhere including India used to initiate deliberate policy measures to reduce these disparities. But with the return of faith in the market mechanism in the liberalized economic scenario of the world to date, there is a tendency to withdraw such measures under the implicit assumption that the invisible hand will deliver the goods in this regard too. India has also witnessed a substantial change in its economic policy particularly since the 1990s. Coming from a closed economic set-up having considerable faith in centralized planning and with commanding authority reserved for the public sector, India has now become a highly liberalized and globalized economy with great belief in the efficiency of the market mechanism. It is hence a matter of considerable research interest to know the manner in which inter-regional disparities in the levels of economic and social development have changed in India over time in the past two decades. A comparison of India's regional development experience over the

Kerala Development Society, Centre for Business Development, New Delhi, India

Received: 31 December 2006 Accepted : 15 October 2007

(C) 日本地域学会（JSRSAI） 2007 
past two decades would therefore give at least a broad idea of the impact, if any, of these changes on regional aspects of India's development.

Before we examine the raison d'être, we have a very brief look at the process of economic reform in India ${ }^{1}$. In view of the extremely serious balance of payment crisis that India faced in 1990-1991, the country was literally forced to adopt a program of economic liberalization initially with the support of the International Monetary Fund (IMF) and the World Bank. Though the country got over its balance of payment crisis in two years and terminated its balance of payments support program with the IMF, successive democratically elected governments in the country have broadened as well as deepened these economic reforms in later years. Many important facets of the policy of economic liberalization were adopted in India. The large number of industries reserved exclusively for the public sector till 1991 was drastically reduced and public sector units that still exist are witnessing disinvestment or are in the process of being privatized. Legal obstacles for getting a license to set up a private firm are being minimized and in some cases even abolished. The Indian rupee was devalued and a floating exchange rate was introduced. International economic transactions have experienced considerable liberalization irrespective of whether we consider imports of goods, capital imports or foreign direct or institutional investment, though the country is yet to have full capital account convertibility. Serious efforts are undertaken to date to reduce fiscal deficits by the central government and the states in India. Measures have also been taken to liberalize the domestic financial sector.

It also appeared, supported by considerable empirical evidence, that contrary to assumptions and some policy measures, economic growth did not trickle down spatially under the command and control regime prevalent earlier ${ }^{2}$. There was serious concern about the fact that some Indian states with large populations and vast natural and mineral resources were pockets of poverty. Since the changes in the boundaries and in the number of states in India aimed to make each state linguistically, culturally and even ethnically more homogeneous these concerns have increased in importance. On top of this, India is also facing the phenomenon of regional parties coming up in the last few years, having a say not only at the concerned state level but also as members of coalition governments at the central level. In such a scenario, widespread inter-state disparities in levels of economic and social development can have serious economic, social and even political consequences, this being particularly so if these have persisted over long periods of time.

One of the reasons for adopting the policy of economic liberalization in a profound way since the 1990s in India was the plea that economic growth would trickle down spatially if market forces are given free play and obstacles preventing growth of the economies of the less developed regions are removed. This might look at first sight to be somewhat puzzling because liberation meant the removal of a number of concessions being offered by both the central and state governments since at least the 1970s to promote industrialization in the less developed regions ${ }^{3}$. Moreover profit-maximizing behavior of entrepreneurs would make them move to the more developed regions in preference to the less developed ones. But as

\footnotetext{
${ }^{1}$ For a detailed discussion of economic reforms in India see, among others, Wadhva [25].

2 See, among others Nair [14].

${ }^{3}$ For a critical discussion on these policy measures see, among others, Nair [14].
} 
pointed out by many including Nair [17], there was also another side of the coin and the argument that economic liberalization may result in the less developed regions of India experiencing faster economic growth than the other regions did, holds somewhat true. One particular policy followed by the central government in India in the pre-reform period proves this point most clearly. According to the notorious freight equalization policy, some industrial raw materials available only in the natural resource rich and less developed states of India, like Bihar and Madhya Pradesh, were made available in the pre-reform period at uniform prices all over India, thereby removing the competitive edge of these mineral resource rich and less developed states in attracting entrepreneurs to set up industrial units requiring these inputs ${ }^{4}$. Further, with economic liberalization, industrial units catering to export-oriented activities were expected to grow substantially in some of the less developed regions, particularly if we consider the fact that the multinational corporations (MNCs), which are likely to be attracted to India due to the opening up of the Indian economy, go for considerable sub-contracting to smaller units. Moreover, with export-orientation in agriculture and industry, crop-patterns may change in favor of commercial crops and there may be considerable development in primary activities in the less developed regions ${ }^{5}$. Thus forces of both divergence and convergence between regions were expected to be unleashed as a result of the shift from a command and control economy to a liberalized one in India in the 1990s.

In view of all this, a study examining the extent and the manner of change of inter-state economic and social disparities in India and drawing broad inferences regarding regional policy in India would be of considerable relevance to policy-makers and planners in India, this being especially so because the period covered by the study includes a decade before the economic reforms and another afterwards. This is all the more so because at the time the study was undertaken, studies of this kind were scarce. A critical survey of studies related to regional economic development in India by Nair [16] has clearly shown a shortage of studies of the type being attempted here till 1990. Earlier work mainly examined issues related to the choice of regions for analysis, estimation of indicators of regional well being, regional impact studies and studies testing the validity of growth theories at the regional level. With a few exceptions like the study by Nair [14] dealing with the pre-1980 period, these studies did not link regional development experience to government policies with regard to regional development. The situation has remained more or less the same since the 1990s. Of course there have been a number of relevant studies about indicators of regional well being like the ones by Cassen [3] and the Planning Commission [19]. See, among others, also Singh et al. [23]. There have also been some attempts to determine the relationship between economic growth and poverty at the regional level like the one by Datt and Ravilion [5], see, among others, also [24]. There were also some efforts in linking regional development experience to regional policy. One of these by Nair [17] was a mere exploratory note and was concerned with just one state - Orissa. The other was a much more detailed one by Kurian [12] and dealt with the major Indian states, but it did not cover

\footnotetext{
${ }^{4}$ See, various explanations of this view relating to the State of Bihar.

${ }^{5}$ Both Harris [9] and Nair [15] have shown that export-led growth is not sustainable if exports are mainly primary products and may result in the depletion of non-renewable resources.
} 
both the pre and the post reform periods. There thus seems as yet to have been no detailed study of this kind looking at inter-state regional experience in economic and social development in India, examining the patterns of regional change and linking all this up with changes in regional policy and covering both the pre and the post-reform periods.

\section{Scope, Data and Methodology}

The states in India are taken as regions for the purpose of the study. However, the question may arise as to whether it is appropriate to consider the states as regions for the purpose of this study ${ }^{6}$. It is true that no Indian state can be looked upon as an entirely homogenous region by any criterion of homogeneity. Nor can it be looked upon as a nodal region, in terms of the existence of only self-contained economic linkages. But it is generally accepted in regional studies that there are no ideal regions for all purposes of regional analysis. The states are the politico-administrative units of the Indian federation, these are also the units for which data are collected and have also some tasks in plan formulation and implementation. Moreover, as a result of many changes in the number and the borders of states since the linguistic reorganization of states in the late 1950s, there now exists considerable linguistic and cultural homogeneity within each state in comparison to what existed in the mid-1950s. Inter-state comparisons of the type being attempted here, however, have to be done with considerable caution on at least two accounts. Firstly, the states differ from each other considerably in terms of area and of population. Secondly, the borders of the different states have undergone great changes over time because of the formation of many new states out of old ones and the conversion of some former Union Territories into states. In view of all this, despite the existence now of twenty-eight states in India, the analysis here is mostly confined to sixteen states for which comparable data are available for the period of analysis. The states studied are Andhra Pradesh, Assam, Bihar including the state of Jharkhand, Gujarat, Himachal Pradesh, Haryana, Karnataka, Kerala, Madhya Pradesh including the state of Chattisgarh, Maharashtra, Orissa, Punjab, Rajasthan, Tamil Nadu, Uttar Pradesh including the state of Uttaranchal, and West Bengal.

As pointed out by many including Nair [15], data problems are a major impediment to a meaningful and in-depth regional analysis even at the state-level in India. Data at the state level are available concerning net domestic product or sources of income which can be considered indicative of the level and efficiency of resource use in the concerned state. These are being regularly published by the statistical bureaus of the concerned states, but there are doubts about the strict comparability of these estimates particularly in making inter-state comparisons. Moreover changes in the methodology of, and data base used in, these estimates make inter-temporal comparisons also difficult. We have also to bear in mind the well-known fact that the state economies have always been much more open than the national economy if we consider the existence of considerable inter-state economic flows. In view of this, no serious analyst would consider the sources of income in a state as indicative of the level of living of the people of the state concerned. In order to have a clearer understanding in this regard, it is necessary to examine other indicators like income

\footnotetext{
${ }^{6}$ For a good discussion in this regard, see among others, Nair [15].
} 
accruing or disposable personal income at the state level. But data regarding income accruing or of personal income, available at the regional level in most countries of the world, are remarkably absent in India. However, in recent years, some serious efforts have been made to fill this important data gap. The Planning Commission [19] has published human development indices (HDI) at the state level for three points of time. Similarly, the Economic and Political Weekly Research Foundation (EPWRF) (2002) has put together on a comparable basis data on per capita net state domestic product (PNSDP) published by the different state statistical bureaus. The data from these two sources are mainly used for the purpose of analysis in this study.

Data limitations, shortness of the period studied and other time and budgetary constraints have limited the nature of the work. No detailed and in-depth analysis of the relationship between regional policy and the nature of inter-state disparities could be carried out. Further, data limitations also hampered the application of advanced statistical and econometric techniques to analyze the data. As pointed out by many including Hanna [8], a usually accepted and simple way of carrying out disaggregated regional analysis of this kind at the sub-national level is to compare the region concerned with the nation as a whole. This is done by working out regional index numbers, which give the position of the region concerned under the assumption that the value for the variable under study at the national level is 100. Due to data limitations, comparisons between two single points of time are avoided and three-year averages are taken. Thus, in order to examine the pattern of regional change in India, PNSDP at constant 1993-94 prices based upon the data published by the EPWRF (2002) have been used to produce average values of state index numbers in PNSDP for the years 1980-81 to 1982-83, 1987-88 to 1989-90, 1991-92 to 1993-94 and 1997-98 to 1999-2000. Three variables indicative of the level of living have been considered. These are the HDI and the share of population below the poverty line (PBPL) as published by the Planning Commission [19], and per capita private consumer expenditure (PCE) for the years $1983,1987-88,1993-94$ and $1998-99$ calculated from the data in the reports of the $38^{\text {th }}, 43^{\text {rd }}, 50^{\text {th }}$ and $55^{\text {th }}$ rounds of the National Sample Survey. Index numbers for states have been calculated on the basis of each of these variables. The pattern of change is examined by looking at the sign of change in these as well as by examining the coefficients of correlation between the values of the state index numbers in the initial year/period and the percentage change in these values between the initial year/period and the terminal year/period have also been calculated. Such analysis is carried out for the pre- and the post-reform periods separately. The purpose is to depict the pattern of regional change with particular attention to see whether there are any differences in this regard between the pre- and the post-reform periods in India. The regions are then grouped into two, group one consisting of regions with values of index numbers less than 100 and group two of regions with values of index numbers equal to or more than 100 . However in the case of PBPL, states with state index numbers equal to or more than 100 form group one with the other states forming group two.

The relative development of the different states is studied by looking at the manner in which these state index numbers undergo change over time. In the case of all variables considered except PBPL, when regional disparities decrease to lead to regional convergence, states of group one experience positive changes in the value of their index numbers, while in 
the case of states of group two state index numbers experience negative changes over time with the exact opposite happening when regional disparities increase to lead to regional divergence. In the case of PBPL, where the grouping has been done in a different manner in the case of regional divergence, states of group one experience positive changes with the reverse happening to states of group two. Besides looking at the inter-temporal movement of states between the two groups in terms of the values of their respective state index numbers, coefficients of correlation are calculated between the value of the state index number in the initial period and changes in this value over time. The significance of the coefficients is tested at the $5 \%$ level on the basis of the two-tailed t-statistic. In order to further facilitate inter-temporal analysis, besides this disaggregated analysis in terms of these regional index numbers, a commonly used summary measure of inter-state variability - inter-state coefficient of variation - is also calculated for each of the variables considered. An examination is then made of the manner in which these coefficients of variation have changed over time.

\section{Prevalent Views}

Regions of a nation are endowed with different natural resources and usually have different historical, sociological and political backgrounds. The assumption, in traditional economic theory, of free and costless mobility of factors of production - labor, capital and entrepreneurship - across the regions of any particular nation hence seldom holds true in actual practice. As a result mainly of all this, it seldom happens that the different regions of a nation are all at the same level of economic development at any point of time. For less developed economies where the levels of living of most people are quite low, the existence of lagging regions, which are also often pockets of poverty, can cause considerable concern. Further as a nation develops economically, the different regions of the nation may or may not share the benefits of this economic development equally. It is hence a matter of great interest to examine the manner in which inter-regional differences in the levels of economic development undergo change during the process of national economic development. If these have a natural tendency to decline in the process of national economic development, and the time taken for this decline is not the proverbial Keynesian long-run in which all of us may be dead, there is no need to devise and rigorously implement deliberate policy measures to mitigate these. On the contrary, if there is an automatic and built-in tendency on economic grounds for these differences to increase with national economic development, policy measures to prevent such increases are definitely called for.

Considerable economic, and, since 1990s, econometric research has continued to unravel the pattern of regional economic change in the process of national economic development. Myrdal [13] and Hirschman [10] have identified in detail the forces that operate to bring about these relative regional changes. While Myrdal [13] refers to the forces of convergence and of divergence as backwash and spread effects, Hirschman [10] describes these broadly as trickling-down and polarization effects, respectively. Scanning regional economic literature, one comes across at least three different hypotheses in this regard and these differ on the emphasis given to the relative importance over time of the forces of convergence and of divergence. One of these is the self-perpetuation hypothesis proposed by Hughes [11] 
and found empirically valid by Booth [2] for the USA. According to this view, the forces of divergence dominate over those of convergence and as a result inter-regional differences in the levels of economic development keep on widening over time. A diametrically opposite view is the convergence hypothesis proposed and found empirically valid by Hanna [8] and substantiated these days also with the Solovian logic that the rate of economic growth is inversely related to the level of per capita income and hence - given identical technologies, preferences and rates of population growth - cotemporaneous differences in per capita incomes between any two regions will be transitory. Considerable evidence to support the hypothesis empirically has been provided by Hanna [8], Perloff et al. [18] and more recently by Sala-i-Martin [20]. The third hypothesis, which in a sense is a happy combination of these two diametrically opposite views is the concentration-cycle hypothesis proposed by Williamson [26]. The proponents of this view point out that inter-regional economic differentials diverge initially to converge later on and thus trace out the famous Kuznetsian inverted U-shaped curve over time in the process of national economic development. Considerable empirical evidence in support of such a view emerged as a result of a detailed international study of regional development experiences by Williamson [26]. A new and valid point being stressed in this regard by many including Nair [14] is that the pattern of regional change depends upon the indicators of development being considered, with different indicators showing different patterns of regional change.

\section{The Pre-Reform Era}

Table 1 gives the state index numbers of Per Capita Net State Domestic Product (PNSDP) at constant 1993-94 prices for the pre-reform period.

The signs of the change in index numbers in column five of the table indicate that there are no definite tendencies toward regional convergence or divergence in the period. Of course one of the states - Kerala - which is in group two at the margin goes down considerably to have a value lower than 100 in the final period of the pre-reform era. The largest as well as the smallest percentage change in index numbers is in states of the group with a value of index numbers equal to or greater than 100 in the initial period of the pre -reform era. Further though three of the seven states of group two undergo negative changes, six of the nine states of group one also undergo negative changes in the value of their index numbers. This gets further strengthened by the fact that the coefficient of correlation between the value of the state index numbers in the initial period of the prereform era and its percentage change during the period is only 0.31 , which is not statistically significant.

State index numbers concerning Human Development Index (HDI), Per Capita Consumer Expenditure (PCE) and Population Below Poverty Line (PBPL) for the pre-reform period are given in Tables 2, 3 and 4 respectively.

The tables indicate that on the whole there has been a tendency of convergence if we look at the signs of the percentage change in the value of the index numbers between the initial and the last years of the pre-reform period. In the case of HDI while seven of the nine states of group two undergo negative changes, six of the seven states of group one undergo positive changes in the value of their index numbers. Actually the coefficient of correlation 
Table 1 Net State Per Capita Domestic Product at constant (1993-94) prices in the pre-reform period (index numbers)*.

\begin{tabular}{|r|l|c|c|r|}
\hline \multirow{2}{*}{ No. } & \multicolumn{1}{|c|}{ State } & $\begin{array}{c}\text { Index } \\
\text { number }\end{array}$ & $\begin{array}{c}\text { Index } \\
\text { number }\end{array}$ & \multirow{2}{*}{ \% change } \\
\cline { 3 - 4 } & & $\begin{array}{c}1980-81 \\
\text { to } 1982-83\end{array}$ & $\begin{array}{c}1987-88 \\
\text { to } 1989-90\end{array}$ & \\
\hline 1 & Bihar & 62.33 & 59.71 & -4.21 \\
2 & Orissa & 71.40 & 70.83 & -0.79 \\
3 & Uttar Pradesh & 77.72 & 74.08 & -4.69 \\
4 & Rajasthan & 80.55 & 82.08 & 1.91 \\
5 & West Bengal & 88.50 & 85.00 & -3.95 \\
6 & Assam & 89.81 & 78.02 & -13.13 \\
7 & Andhra Pradesh & 90.97 & 90.64 & -0.37 \\
8 & Karnataka & 93.26 & 94.39 & 1.21 \\
9 & Madhya Pradesh & 93.92 & 83.27 & -11.34 \\
\hline 10 & Tamil Nadu & 100.16 & 102.41 & 2.25 \\
11 & Kerala & 101.87 & 88.24 & -13.38 \\
12 & Himachal Pradesh & 105.87 & 101.52 & -4.11 \\
13 & Gujarat & 122.33 & 119.94 & -1.96 \\
14 & Maharashtra & 131.08 & 131.78 & 0.53 \\
15 & Haryana & 140.33 & 143.96 & 2.59 \\
16 & Punjab & 162.00 & 164.91 & 1.80 \\
\hline
\end{tabular}

Note *States are arranged in ascending order of the value of the index numbers in the initial period, which refers to $1980-81$ to $1982-83$. The last period refers to 1987-88 to $1989-90$.

Source Calculated from Economic and Political Weekly Research Foundation (EPWRF) (2002) : Domestic Product of States of India $1960-61$ to $2000-01$.

Table 2. Human Development Index per state in 1981 and 1991 (index numbers)*

\begin{tabular}{|r|l|c|r|r|}
\hline \multirow{2}{*}{ No. } & \multicolumn{1}{|c|}{ State } & \multicolumn{2}{|c|}{ Index numbers } & \multirow{2}{*}{ \% change } \\
\cline { 3 - 4 } & & 1981 & 1991 & \\
\hline 1 & Bihar & 78.48 & 80.84 & 3.01 \\
2 & Madhya Pradesh & 81.13 & 86.09 & 6.12 \\
3 & Uttar Pradesh & 84.44 & 82.41 & -2.40 \\
4 & Rajasthan & 84.77 & 91.08 & 7.44 \\
5 & Orissa & 88.41 & 90.55 & 2.42 \\
6 & Assam & 90.07 & 91.34 & 1.41 \\
7 & Andhra Pradesh & 98.68 & 98.95 & 0.28 \\
\hline 8 & West Bengal & 100.99 & 106.04 & 4.99 \\
9 & Tamil Nadu & 113.58 & 122.31 & 7.69 \\
10 & Karnataka & 114.57 & 108.14 & -5.61 \\
11 & Gujarat & 119.21 & 113.12 & -5.10 \\
12 & Haryana & 119.21 & 116.27 & -2.46 \\
13 & Maharashtra & 120.20 & 118.64 & -1.30 \\
14 & Himachal Pradesh & 131.79 & 123.10 & -6.59 \\
15 & Punjab & 136.09 & 124.67 & -8.39 \\
16 & Kerala & 165.56 & 155.12 & -6.31 \\
\hline
\end{tabular}

Note *States are arranged in ascending order of index numbers in the initial year.

Source Human Development Report 2001, Planning Commission. 
Table 3. Per Capita Private Consumer Expenditure per state in the pre-reform period (index numbers)*

\begin{tabular}{|r|l|r|r|r|}
\hline \multirow{2}{*}{ No. } & \multicolumn{1}{|c|}{ State } & \multicolumn{2}{|c|}{ Index numbers } & \multirow{2}{*}{$\%$ change } \\
\cline { 3 - 4 } & & 1983 & $1987-88$ & \\
\hline 1 & Bihar & 79.54 & 78.76 & -0.98 \\
2 & Orissa & 83.16 & 77.36 & -6.98 \\
3 & Uttar Pradesh & 88.27 & 89.24 & 1.10 \\
4 & Madhya Pradesh & 89.20 & 90.12 & 1.03 \\
5 & Assam & 94.20 & 91.63 & -2.73 \\
6 & West Bengal & 97.52 & 97.53 & 0.00 \\
\hline 7 & Andhra Pradesh & 100.91 & 98.49 & -2.40 \\
8 & Tamil Nadu & 103.44 & 102.66 & -0.75 \\
9 & Karnataka & 106.14 & 94.59 & -10.88 \\
10 & Gujarat & 106.76 & 103.78 & -2.79 \\
11 & Rajasthan & 107.49 & 105.42 & -1.93 \\
12 & Maharashtra & 110.74 & 113.75 & 2.72 \\
13 & Kerala & 121.58 & 124.32 & 2.25 \\
14 & Haryana & 125.49 & 123.15 & -1.87 \\
15 & Himachal Pradesh & 126.68 & 121.85 & -3.81 \\
16 & Punjab & 139.26 & 138.56 & -0.51 \\
\hline
\end{tabular}

Note *States are arranged in ascending order of index numbers in the initial year, which refers to 1983 on the basis of the 38th Round of the NSS. The final year refers to 1987-88 corresponding to the 43rd Round of the NSS.

Table 4. Share of Population below Poverty Line per state in the pre-reform period (index numbers)*

\begin{tabular}{|r|l|r|r|r|}
\hline \multirow{2}{*}{ No. } & \multicolumn{1}{|c|}{ State } & \multicolumn{2}{|c|}{ Index numbers } & \multirow{2}{*}{$\%$ change } \\
\cline { 3 - 4 } & & 1983 & $1987-88$ & \\
\hline 1 & Orissa & 146.79 & 143.03 & -2.56 \\
2 & Bihar & 139.88 & 134.15 & -4.10 \\
3 & West Bengal & 123.31 & 115.08 & -6.68 \\
4 & Tamil Nadu & 116.14 & 111.66 & -3.86 \\
5 & Madhya Pradesh & 111.92 & 110.83 & -0.97 \\
6 & Uttar Pradesh & 105.82 & 106.69 & 0.82 \\
\hline 7 & Maharashtra & 97.66 & 103.99 & 6.48 \\
8 & Assam & 90.98 & 93.18 & 2.41 \\
9 & Kerala & 90.87 & 81.81 & -9.98 \\
10 & Karnataka & 85.97 & 96.58 & 12.34 \\
11 & Rajasthan & 77.47 & 90.45 & 16.75 \\
12 & Gujarat & 73.72 & 81.16 & 10.10 \\
13 & Andhra Pradesh & 65.00 & 66.55 & 2.39 \\
14 & Haryana & 48.04 & 42.82 & -10.87 \\
15 & Himachal Pradesh & 36.87 & 39.76 & 7.83 \\
16 & Punjab & 36.38 & 33.97 & -6.62 \\
\hline
\end{tabular}

Note *States are arranged in descending order of index numbers in the initial year, which refers to 1983 on the basis of the 38th Round of the NSS. The final year refers to 1987-88 corresponding to the 43rd Round of the NSS. Source Human Development Report 2001, Planning Commission. 
between the value of the index number in the initial year and the percentage change in it is negative. The value is as large as -0.70 and it is significant. As regards state index numbers in PCE, the signs of change in these do indicate a tendency towards convergence. In fact, two of the seven states of group two - Andhra Pradesh and Karnataka shift from group two to group one during the period. It is also true that seven of the ten states of group two experience a decline in the value of their index numbers. But only three of the six states of group one undergo positive changes in this regard. As a result, no definite conclusion can be drawn in this regard, particularly since the coefficient of correlation between the value of the state index numbers in the initial year and the percentage change in it during the period is 0.09 , and it is not significant. The changes in the index numbers in PBPL also give some indications of regional convergence in poverty reduction. The relative positions of five of the six states of group one undergo a decline while six of the ten states of group two experience an increase in their relative positions in this regard, with the state of Maharashtra changing during the period from group two to group one as a result. These changes are however not reflected in the coefficient of correlation between state index numbers in the initial year and the percentage change in it during the period. The value of this coefficient is of course negative but it is only -0.18 and not significant.

\section{The Post-Reform Period}

Table 5 gives the state index numbers of PNSDP at constant 1993-94 prices for the postreform period.

The signs of the changes given in column five of the table indicate that there are definite tendencies towards regional divergence in the post-reform period. Six of the nine states of group one experience negative changes. The largest negative change is in Assam. What seems even more striking is the fact that the second and third largest negative changes have taken place in the least developed states of India - Bihar and Uttar Pradesh. Four of the six states of group two undergo positive changes in their index numbers and the largest positive change has in fact taken place in one of the most developed states of India Gujarat. All this is reflected in the fact that the correlation coefficient between the index numbers in the initial year and its percentage change during the post-reform period is positive and has a value of 0.35 which is higher than the one in the pre-reform period. Nothing definite can however be said on the basis of this value because it is not significant.

Index numbers for states concerning HDI, PCE and PBPL for the post-reform period are given in Tables 6, 7 and 8 respectively.

The tables indicate that while the converging tendency of HDI continues in the postreform period also, there are definite tendencies of inter-regional divergence if we consider PCE and PBPL. Nothing can be said in this regard on the basis of the signs of change of index numbers of HDI because they are all negative ${ }^{8}$. The coefficient of correlation between the value of the index numbers in the initial year and the percentage change in it during the

\footnotetext{
${ }^{7}$ In terms of poverty reduction, regional convergence means that states of group one experience negative changes in relative position with the reverse happening to states of group two, since the grouping is in descending order of the state index numbers in this case.

8 This could be because a number of states have been left out.
} 
Table 5. Per Capita Net State Domestic Product at constant (1993-94) prices in the post-reform period (index numbers)*

\begin{tabular}{|c|l|c|c|r|}
\hline \multirow{2}{*}{ No. } & \multicolumn{1}{|c|}{ State } & $\begin{array}{c}\text { Index } \\
\text { number }\end{array}$ & $\begin{array}{c}\text { Index } \\
\text { number }\end{array}$ & \\
\cline { 3 - 4 } & & $\begin{array}{c}1991-82 \\
\text { to } 1993-94\end{array}$ & $\begin{array}{c}1997-98 \\
\text { to } 1999- \\
2000\end{array}$ & \\
\hline 1 & Bihar & 51.20 & 41.93 & -18.11 \\
2 & Orissa & 62.23 & 53.65 & -13.78 \\
3 & Uttar Pradesh & 69.30 & 56.78 & -18.07 \\
4 & Assam & 74.84 & 59.55 & -20.42 \\
5 & Madhya Pradesh & 81.33 & 75.85 & -6.74 \\
6 & Rajasthan & 85.01 & 89.03 & 4.73 \\
7 & West Bengal & 86.34 & 90.58 & 4.92 \\
8 & Andhra Pradesh & 94.01 & 91.50 & -2.67 \\
9 & Kerala & 97.19 & 98.50 & 1.34 \\
\hline 10 & Karnataka & 100.14 & 105.88 & 5.73 \\
11 & Himachal Pradesh & 101.52 & 103.29 & 1.74 \\
12 & Tamil Nadu & 111.64 & 120.87 & 8.27 \\
13 & Gujarat & 123.63 & 134.78 & 9.02 \\
14 & Haryana & 146.21 & 133.95 & -8.38 \\
15 & Maharashtra & 147.12 & 146.20 & -0.63 \\
16 & Punjab & 164.06 & 146.78 & -10.54 \\
\hline
\end{tabular}

Note: *States are arranged in ascending order of index numbers in the initial period, which refers to 1991-92 to 1993-94. The final period refers to 1997-98 to 1999-2000. Source Calculated from Economic and Political Weekly Research Foundation (EPWRF) (2002) : Domestic Product of States of India $1960-61$ to $2000-01$.

Table 6. Human Development Index per state, in 1991 and 2001 (index numbers)*

\begin{tabular}{|r|l|r|r|r|}
\hline \multirow{2}{*}{ No. } & \multicolumn{1}{|c|}{ State } & \multicolumn{2}{|c|}{ Index numbers } & \multirow{2}{*}{ \% change } \\
\cline { 3 - 4 } & & 1991 & 2001 & \\
\hline 1 & Bihar & 80.84 & 77.75 & -3.82 \\
2 & Uttar Pradesh & 82.41 & 82.20 & -0.26 \\
3 & Madhya Pradesh & 86.09 & 83.47 & -3.04 \\
4 & Orissa & 90.55 & 85.59 & -5.48 \\
5 & Rajasthan & 91.08 & 89.83 & -1.37 \\
6 & Assam & 91.34 & 81.78 & -10.47 \\
7 & Andhra Pradesh & 98.95 & 88.14 & -10.93 \\
\hline 8 & West Bengal & 106.04 & 100.00 & -5.69 \\
9 & Karnataka & 108.14 & 101.27 & -6.35 \\
10 & Gujarat & 113.12 & 101.48 & -10.29 \\
11 & Haryana & 116.27 & 107.84 & -7.25 \\
12 & Maharashtra & 118.64 & 110.81 & -6.60 \\
13 & Tamil Nadu & 122.31 & 112.50 & -8.02 \\
14 & Punjab & 124.67 & 113.77 & -8.74 \\
15 & Kerala & 155.12 & 135.17 & -12.86 \\
\hline
\end{tabular}

Note: *States are arranged in ascending order of index numbers in the initial year.

Source: Human Development Report 2001, Planning Commission 
Table 7. Per Capita Private Consumer Expenditure per state in the post-reform period (index numbers)*

\begin{tabular}{|r|l|c|c|c|}
\hline \multirow{2}{*}{ No. } & \multicolumn{1}{|c|}{ State } & $\begin{array}{c}\text { Index } \\
\text { number }\end{array}$ & $\begin{array}{c}\text { Index } \\
\text { number }\end{array}$ & \multirow{2}{*}{$\%$ change } \\
\cline { 3 - 4 } & & $1993-94$ & $1999-2000$ & \\
\hline 1 & Bihar & 72.15 & 70.59 & -2.16 \\
2 & Orissa & 74.94 & 70.00 & -6.59 \\
3 & Assam & 85.45 & 80.11 & -6.25 \\
4 & Madhya Pradesh & 88.31 & 81.04 & -8.24 \\
5 & Uttar Pradesh & 90.69 & 87.48 & -3.54 \\
6 & Karnataka & 97.04 & 108.09 & 11.39 \\
7 & Andhra Pradesh & 98.20 & 93.16 & -5.14 \\
\hline 8 & West Bengal & 101.58 & 96.73 & -4.77 \\
9 & Tamil Nadu & 104.91 & 115.29 & 9.89 \\
10 & Rajasthan & 105.61 & 103.42 & -2.08 \\
11 & Gujarat & 108.74 & 114.77 & 5.54 \\
12 & Maharashtra & 113.21 & 118.01 & 4.24 \\
13 & Himachal Pradesh & 117.69 & 124.85 & 6.08 \\
14 & Haryana & 124.22 & 129.94 & 4.60 \\
15 & Kerala & 127.70 & 138.20 & 8.23 \\
16 & Punjab & 139.13 & 134.03 & -3.67 \\
\hline
\end{tabular}

Note: *States are arranged in ascending order of index numbers in the initial year, which refers to 1993-94 on the basis of the 50th Round of the NSS. The last year refers to 1999-2000 corresponding to the 55th Round of the NSS. Source: Human Development Report 2001, Planning Commission.

Table 8 Share of Population below Poverty Line per state in the post-reform period (index numbers)*

\begin{tabular}{|c|l|c|c|c|}
\hline \multirow{2}{*}{ No. } & \multicolumn{1}{|c|}{ State } & $\begin{array}{c}\text { Index } \\
\text { number }\end{array}$ & $\begin{array}{c}\text { Index } \\
\text { number }\end{array}$ & \multirow{2}{*}{$\%$ change } \\
\cline { 3 - 4 } & & $1993-94$ & $1999-2000$ & \\
\hline$(1)$ & $(2)$ & $(3)$ & $(4)$ & $(5)$ \\
\hline 1 & Bihar & 152.79 & 163.22 & 6.82 \\
2 & Orissa & 118.21 & 140.65 & 33.81 \\
3 & Madhya Pradesh & 113.59 & 138.28 & 21.32 \\
4 & Assam & 113.57 & 119.35 & 21.73 \\
5 & Uttar Pradesh & 102.47 & 95.86 & -6.45 \\
6 & Maharashtra & 99.14 & 103.52 & 4.42 \\
\hline 7 & West Bengal & 97.39 & 80.92 & -16.91 \\
8 & Tamil Nadu & 92.19 & 76.78 & -16.71 \\
9 & Karnataka & 79.07 & 29.23 & -63.03 \\
10 & Himachal Pradesh & 76.20 & 58.54 & -23.17 \\
11 & Rajasthan & 70.70 & 48.74 & -31.06 \\
12 & Kerala & 69.64 & 33.49 & -51.92 \\
13 & Haryana & 67.31 & 53.91 & -19.91 \\
14 & Gujarat & 61.69 & 60.42 & -2.06 \\
15 & Andhra Pradesh & 32.72 & 23.60 & -27.87 \\
16 & Punjab &
\end{tabular}

Note: *States are arranged in descending order of index numbers in the initial year, which refers to 1993-94 on the basis of the 50th Round of the NSS. The last year refers to 1999-2000 corresponding to the 55th Round of the NSS. 
period is negative and significant having a value of -0.69 , which is almost the same as in the pre-reform period. There are however indications of regional divergence if we consider PCE. Six of the seven states of group one undergo negative changes in the value of their index numbers and six of the nine states of group two undergo positive changes in their relative positions in the post-reform period. Actually the correlation coefficient between the value of the index numbers in the initial period and the percentage change in it over time is positive and as high as 0.46 , though not statistically significant. As regards PBPL, there has on the whole been a tendency of divergence if we look at the signs of the percentage change in the value of the index numbers between the initial and the final years of the postreform period. Five of the six states of group one undergo positive changes with Orissa one of the least developed states of India - experiencing the largest positive increase. Only one of the ten states of group two undergoes a positive change in this regard. The coefficient of correlation between the initial value of the index number and its percentage change is positive in the post-reform period in contrast with the pre-reform one. The value however is only 0.21 and is not statistically significant ${ }^{9}$.

\section{Comparison of the Two Periods}

A comparison of the results of the pre- and the post-reform periods on the basis of state index numbers suggests that the manner of change in the two periods has been somewhat different. Another finding also stands out quite clearly. Irrespective of whether we are concerned with the pre- or post-reform era, the analysis suggests that the pattern of regional change depends upon the variable considered There are even clearer indications in this regard if we examine the inter-state coefficients of variation the values of which are given in Table 9 .

In the case of PNSDP, there actually seems to have been some divergence even in the pre-reform period, which continues in the post-reform one. The more or less continuous decline in regional disparities in HDI is quite noticeable in the case of the coefficient of variation too. As regards PCE and PBPL, there is more definite evidence of a slight convergence in the pre-reform period and quite noticeable divergence in the post-reform one.

\section{Inferences}

The preliminary analysis on the basis of the latest available data has revealed that the patterns of regional change in the pre- and post-reform periods have been somewhat different. As regards per capita PNSDP, while there are no definite indications of either divergence or convergence at the regional level in the pre-reform era considered here, the evidence points towards divergence in the post-reform period. According to some, including Cassen [3], this needs not cause much concern since regional divergence in PNSDP has been a tendency prevalent in India since the 1950s. One is however constrained to dispute such a contention. This is so because on the basis of very detailed regional analysis, many researchers in India including Dholakia [6] and Nair [14] hold the view that India had almost reached the turning point of the concentration-cycle hypothesis in this regard by the late

\footnotetext{
9 There have been criticisms of the new reference period adopted for the $55^{\text {th }}$ round of the NSS and if we use data adjusted for this difference, the coefficient is 0.68 and it is significant.
} 
Table 9. Inter-state Coefficients of Variation, 1980-2000*

\begin{tabular}{|c|l|}
\hline \multicolumn{1}{|c|}{ Variable } & $\begin{array}{c}\text { Coefficient of } \\
\text { Variation }\end{array}$ \\
\hline Per Capita Net State Domestic Product (PNSDP) & \\
$1980-81$ to 1982-83 & 25.59 \\
$1987-88$ to 1989-90 & 27.53 \\
$1991-92$ to 1993-94 & 30.97 \\
$1997-98$ to 1999-2000 & 32.42 \\
\hline Human Development Indices (HDI) & $24.60(24.04)^{* *}$ \\
1981 & $20.42(20.25)^{* *}$ \\
1991 & 15.56 \\
2001 & \\
\hline Per Capita Private Consumer Expenditure (PCE) & 17.03 \\
1983 & 16.97 \\
$1987-88$ & 18.30 \\
$1993-94$ & 21.95 \\
$1999-2000$ & \\
1983 & 33.80 \\
$1987-88$ & 32.34 \\
$1993-94$ & 30.24 \\
$1999-2000$ & 49.03 \\
\hline Share of Population Below Poverty Line (PBPL) &
\end{tabular}

* Data sources are in the text (section 2).

** Figures in brackets are the values of the coefficient of inter-state variation excluding the state of Himachal Pradesh; the HDI figure for 2001 is not available.

1970s. Further, there is some evidence in this study to prove that there has not been much regional divergence in this regard between the 1980s and the 1990s. In view of all this, the noticed regional divergence in PNSDP in the post-reform period since the 1990s should be a matter of some concern. A more worrisome situation is that if we consider indicators of levels of living, there are signs of inter-state convergence in the pre-reform period, while there are definite indications of inter-state divergence in the post-reform one. The fact that this has happened despite a decline in regional disparities in HDI should cause serious doubts about the possibility of inter-spatial trickling down of economic growth even if there are improvements in social infrastructure in the less developed regions

The study seems to substantiate the view that the pattern of regional economic change depends upon the indicator of economic development considered as has been argued in the multi-pattern hypothesis in this regard. It has of course to be borne in mind that we have looked at convergence and divergence in a non-econometric sense and have not examined sigma or beta convergence which involve inter-temporal analysis of single summary measures of inter-regional dispersion and relationship between rates of growth and base year values of the indicator under study for the different regions respectively. Besides lending credence to findings on the basis of much earlier data by many including Nair [14] from the 1950 s to the 1980s, the evidence here seems to be in line also with the results of some detailed 
studies using data for recent years like the ones by Dholakia [7], Shetty [21] and Bhattacharya and Sakthivel [1]. Recent econometric studies using data for much longer periods also seem to lead to similar inferences. Das [4] compares interstate movements in real wage rates in agriculture between the years $1956-57$ to $1992-93$ to conclude that there are no indications of continued divergence with some indications also of convergence. Shaban [22] on the other hand finds clear indications of divergence on the basis of his analysis of data on per capita NSDP between the years 1960-61 to 1996-97.

\section{Acknowledgement}

The author, a former Professor at the University of Delhi, is currently affiliated with the Centre for Policy Research (CPR) in New Delhi as an Honorary Research Professor. The findings presented here are mostly based on some of the results of a larger study by the author entitled "Economic Reforms and Regional Disparities in Economic and Social Development in India" funded by the Planning Commission of the Government of India. The author wishes to thank the participants of a seminar at the CPR and at the RSAI symposium at the Indian Institute of Management, Bangalore, and also an anonymous referee of this volume for critical comments on earlier versions of the paper. The usual disclaimers of course apply.

\section{References}

[1] Bhattacharya, B.B., and Sakthivel, S., Regional Growth and Disparity in India, Economic and Political Weekly (EPW), March 6, 2004, pp. 1071-1077.

[2 ] Booth, E.J.R., "Inter-regional Income Differences," Southern Economic Journal (SEJ), Vol. 31, No. 1, July, 1964, pp. 44-51.

[ 3 ] Cassen, R.H., "Well-being in the 90's: Towards a Balance Sheet," EPW, Vol. 37, No. 27, 2002, pp. 2789-2794.

[ 4 ] Das, T.K., "Convergence Across Indian States: cross-sectional and Panel Estimations," South Asia Economic Journal, Vol. 3, No. 2, 2002, pp. 227-239.

[ 5 ] Datt, G., and Ravallion, M., "Is India's Economic Growth Leaving the Poor Behind ?," Mimeographed paper at World Bank Workshop on Poverty Estimates, New Delhi, January, 2002.

[6 ] Dholakia, R.H., Regional Disparity in Economic growth in India, Himalaya, New Delhi, 1985.

[ 7 ] Dholakia, R.H., Regional Disparity in Economic and Human Development in India, RBI Chair Lecture, IIM, Ahmedabad, 2003.

[ 8 ] Hanna, F.A., State Income Differentials 1919-1954, Duke University Press, Durham, 1959.

[ 9 ] Harris, N., "Manufactured Exports and Industrialization: Mexican Case," Economic and Political Weekly, Vol. 26, Nos. 11-12, 1991, pp. 659-668.

[10] Hirschman, A.O., The Strategy of Economic Development, Yale University Press, New Haven, 1961.

[11] Hughes, R.B., "Inter-regional Income Differences: Self-Perpetuation," Southern Economic Journal, Vol. 28, No. 1, July, 1961, pp. 41-45.

[12] Kurian, N.J., "Widening Regional Disparities in India: Some Indicators," $E P W$, Vol. 35, No. 7, 2000, pp. 538-555.

[13] Myrdal, G., Economic Theory and Underdeveloped Regions, Vora, Bombay, 1958.

[14] Nair, K.R.G., Regional Experience in a Developing Economy, Wiley-Eastern, New Delhi, 1982.

[15] Nair, K.R.G., Export-led Economic Development: the Regional Experience of India and Canada, Paper presented at the Conference of the Indian Association of Canadian Studies, Ahmedabad, January, 1992. 
[16] Nair, K.R.G., Regional Economics: A Survey Report, Indian Council of Social Science Research, New Delhi, 1993a.

[17] Nair, K.R.G., "The New Economic Policy and the Development of Backward Regions : A Note On Orissa”, EPW, Vol. 28, No. 19, 1993b, pp. 939-941.

[18] Perloff, H.S., Dunn Jr, E.S., Lampard, E.E., and Muth, R.F., Regions, Resources and Economic Growth, Resources for the Future, Johns Hopkins Press, Baltimore, 1960.

[19] Planning Commission, National Human Development Report 2001, Government of India, New Delhi, 2002.

[20] Sala-i-Martin, X., "Regional Cohesion: Evidence and Theories of Regional Growth and Convergence,” European Economic Review, Vol. 40, 1996, pp. 1325-1352.

[21] Shetty, S.L., "Growth of SDP and Structural Changes in State Economies: Inter-State Comparisons," EPW, Vol. 38, No. 49, December 6, 2003, pp. 5189-5200.

[22] Shaban, Abdul, "Growth and Disparities of Incomes Across States", Man and Development, September, 2002, pp. 31-47.

[23] Singh, Nirvikar, Bhanadari, L., Chen, A., and Khare, A., "Regional Inequality in India: A Fresh Look,” EPW, Vol. 38, No. 11, March 15, 2003, pp. 1069-1073.

[24] Sundaram, K., and Tendulkar, S.D., "Poverty in India in the 1990s", EPW, Vol. 38, No. 14, April 5, 2003, pp. 1385-1394.

[25] Wadhva, C.D., "India Trying to Liberalise: Economic Reforms since 1991," in Jim Rolfe (2004) (ed), The Asia-Pacific: A Region in Transition, Asia Pacific Centre for Security Studies, Honolulu, 2004, pp. 259-284.

[26] Williamson, J.G., "Regional Inequality and the Process of National Development: A Description of the Patterns," Economic Development and Cultural Change, Vol. 13, No. 4, Part II, July, 1965, pp. 1-84.

Website :

EPWRF : www.epwrf.res.in, 2002 